\title{
ORIGINAL
}

\section{A multicenter, randomized, double-blind study of ulimorelin and metoclopramide in the treatment of critically ill patients with enteral feeding intolerance: PROMOTE trial}

Daren K. Heyland', Arthur R. H. van Zanten², Teodoro Grau-Carmona ${ }^{3}$, David Evans ${ }^{4}$, Albertus Beishuizen", Jeroen Schouten ${ }^{6}$, Oscar Hoiting ${ }^{6}$, Maria Luisa Bordejé7, Kenneth Krell ${ }^{8}$, David J. Klein ${ }^{9}$, Jesus Gonzalez ${ }^{10}$, Aitor Perez ${ }^{10}$, Randy Brown ${ }^{11}$, Joyce James ${ }^{11}$, M. Scott Harris ${ }^{11,12^{*}}$ (I) and the Investigators of the PROMOTE LP101-CL-201 Trial

(c) 2019 Springer-Verlag GmbH Germany, part of Springer Nature

\begin{abstract}
Purpose: Enteral feeding intolerance (EFI) is a frequent problem in the intensive care unit (ICU), but current prokinetic agents have uncertain efficacy and safety profiles. The current study compared the efficacy and safety of ulimorelin, a ghrelin agonist, with metoclopramide in the treatment of EFI.

Methods: One hundred twenty ICU patients were randomized 1:1 to ulimorelin or metoclopramide for 5 days. EFI was diagnosed by a gastric residual volume (GRV) $\geq 500 \mathrm{ml}$. A volume-based feeding protocol was employed, and enteral formulas were standardized. The primary end point was the percentage daily protein prescription (\%DPP) received by patients over 5 days of treatment. Secondary end points included feeding success, defined as $80 \%$ DPP; gastric emptying, assessed by paracetamol absorption; incidences of recurrent intolerance (GRV $\geq 500 \mathrm{ml})$; vomiting or regurgitation; aspiration, defined by positive tracheal aspirates for pepsin; and pulmonary infection.
\end{abstract}

Results: One hundred twenty patients were randomized and received the study drug (ulimorelin 62, metoclopramide 58). Mean APACHE II and SOFA scores were 21.6 and 8.6, and $63.3 \%$ of patients had medical reasons for ICU admission. Ulimorelin and metoclopramide resulted in comparable \%DPPs over 5 days of treatment (median [Q1, Q3]: $82.9 \%[38.4 \%, 100.2 \%]$ and $82.3 \%[65.6 \%, 100.2 \%]$, respectively, $p=0.49)$. Five-day rates of feeding success were $67.7 \%$ and $70.6 \%$ when terminations unrelated to feeding were excluded, and there were no differences in any secondary outcomes or adverse events between the two groups.

Conclusions: Both prokinetic agents achieved similar rates of feeding success, and no safety differences between the two treatment groups were observed.

Keywords: Ulimorelin, Metoclopramide, PROMOTE, Enteral feeding intolerance, Volume-based feeding, Gastric residual volume

\footnotetext{
*Correspondence: harris@middleburgconsultants.com

${ }^{11}$ Lyric Pharmaceuticals, San Francisco, CA, USA

Full author information is available at the end of the article

The Investigators of the PROMOTE LP101-CL-201 Trial are listed in Acknowledgements.
} 


\section{Introduction}

Enteral feeding intolerance (EFI), defined as the inability to deliver adequate enteral nutrition to critically ill patients due to delayed gastric emptying in the absence of mechanical obstruction, is a frequent problem in critically ill patients. Observational studies and metaanalyses have revealed that $>30 \%$ of critically ill patients experience intolerance to enteral feeding and that these patients have longer intensive care unit (ICU) stays and higher mortality compared with the tolerant population $[1,2]$.

EFI is most commonly diagnosed by the presence of high gastric residual volume (GRV). Elevated GRV has been shown to predict delayed gastric emptying and portend worse ICU prognosis [3, 4]. A GRV of $500 \mathrm{ml}$ is the recommended threshold for EFI diagnosis in US and European critical care and nutrition society guidelines [5-7].

Prokinetic agents are recommended to promote GI motility and facilitate enteral feedings in patients with EFI $[8,9]$. Metoclopramide, the most commonly used agent, has been associated with delirium, agitation, QT prolongation and sudden cardiac death [10]. Erythromycin has been associated with drug-drug interactions, QT prolongation and super-infection with multiple drugresistant organisms [9]. While the synergy of these drugs has been reported, both agents may rapidly lose effectiveness [11], and neither is approved by regulatory agencies for EFI treatment.

Ghrelin is a naturally occurring peptide and a potent stimulator of growth hormone $(\mathrm{GH})$ secretion and gastric emptying [12, 13]. It possesses anticatabolic and anti-inflammatory properties that could be beneficial in critical illness [14-18]. Ulimorelin, an intravenous, selective synthetic ghrelin agonist, has been studied in over 900 subjects in clinical trials without effects on the central nervous system (CNS) or QT interval [19-21].

The purpose of this trial was to evaluate the efficacy and safety of ulimorelin in critically ill patients with EFI. The hypothesis was that ulimorelin would be superior to metoclopramide in improving nutritional intake with enhanced safety. Because metoclopramide represents the standard of care for EFI treatment at most institutions [9], the study was designed to compare the efficacy and safety of ulimorelin with metoclopramide in this condition.

\section{Methods}

\section{Study design}

This was a randomized, double-blind, comparator-controlled study conducted at 20 sites in the USA, Canada, Spain and The Netherlands between October 2016 and

\section{Take-home message}

In this randomized controlled trial of ulimorelin, a ghrelin agonist, and metoclopramide in critically ill patients with enteral feeding intolerance (EFI), no differences in feeding outcomes or adverse events were observed. Both groups achieved high rates of feeding success with low rates of vomiting and aspiration.

March 2018. The Institutional Review Boards (IRBs)/ Independent Ethics Committees (ECs) approved the study protocol at all participating sites. Informed consent was obtained from the patient's legally authorized representative or proxy, as required by national laws, respective regulations and IRB/ECs. Translations were provided for non-English-speaking patients. Whenever possible, written informed consent was sought from the patient as soon as he/she became capable of comprehending the scope of the study. All study procedures were consistent with Good Clinical Practice Guidelines and followed the Declaration of Helsinki for protection of human subjects.

This study was overseen by an independent data monitoring committee. The trial was registered in ClinicalTrials.gov (NCT02784392) and EUDRACT (2016-000723-94).

\section{Study population}

Patients were eligible for study participation if they were in the ICU, intubated and mechanically ventilated and intolerant to gastric tube feedings. EFI was defined as a GRV $\geq 500 \mathrm{ml}$ on one or more measurements. Patients were required to have $\mathrm{a} \geq 12$-Fr feeding tube and expected to remain intubated, mechanically ventilated and receiving gastric tube feedings for $\geq 48 \mathrm{~h}$. Patients were excluded from the study for use of prokinetic medications within $48 \mathrm{~h}$; weight $>150 \mathrm{~kg}$; pregnancy; suspicion of active bowel obstruction, perforation or leakage; esophageal or gastric surgery prior to or during the current hospitalization; a history of gastroparesis; Child's C cirrhosis; QT interval by Fridericia's formula (QTcF) $>450 \mathrm{~ms}$ on a 12-lead ECG or rapid deterioration. When $50 \%$ of patients had enrolled, the QTcF restriction was liberalized to $480 \mathrm{~ms}$.

\section{Study intervention}

Patients were randomized 1:1 to ulimorelin $(600 \mu \mathrm{g} / \mathrm{kg})$ or metoclopramide $(10 \mathrm{mg})$ administered as a $50-\mathrm{ml} \mathrm{IV}$ infusion over 30 min every $8 \mathrm{~h}$ for 5 days.

Ulimorelin was supplied as a sterile solution of ulimorelin $\cdot \mathrm{HCl}$ monohydrate $(2 \mathrm{mg} / \mathrm{ml})$ in water; metoclopramide injection $(5 \mathrm{mg} / \mathrm{ml})$ was supplied as a sterile solution in single-use vials. The dose of metoclopramide was reduced $50 \%$ in patients with creatinine clearance $\leq 40 \mathrm{ml} / \mathrm{min}$ by the Cockcroft-Gault formula and 
by $75 \%$ for patients whose clearance was $\leq 10 \mathrm{ml} / \mathrm{min}$ or who were on dialysis or continuous renal replacement techniques [22].

The randomization schedule was generated with SAS software (SAS Institute Inc., Cary, NC, USA) using a blocked randomization scheme and a block size of 4. Study medications were prepared by an unblinded pharmacist to ensure correct treatment assignment. Standard operating procedures assured that all other operational personnel remained blinded to treatment assignment.

\section{Study procedures}

The daily protein prescription (DPP) and daily caloric prescription (DCP) were set based on the clinical condition of the patient and to achieve no less than $1.2 \mathrm{~g}$ protein $/ \mathrm{kg}$ body weight and $25 \mathrm{kcal} / \mathrm{kg}$ per $24-\mathrm{h}$ period based on estimated dry weight of the patient at ICU admission. Feedings in obese patients $(\mathrm{BMI} \geq 30)$ were adjusted by adding $25 \%$ of the differences between estimated dry weight and ideal body weight (IBW) to the DPP and DCP, using a standard formula for IBW [23]. Oral protein supplements were permitted in obese patients, but they were not included in the assessment of the primary end point.

A volume-based feeding protocol was employed to compensate for enteral nutrition missed because of interruptions to feeding for procedures or other interventions [24] (Supplementary Fig. 1). To minimize the effects of different enteral formula contents on gastric emptying, formulas were restricted to products containing $125-133 \mathrm{kcal}, 6.2-7.0 \mathrm{~g}$ protein and $3.4-4.9 \mathrm{~g}$ fat per $100 \mathrm{ml}$. Blood glucose was maintained to a target glucose $<180 \mathrm{mg} / \mathrm{dl}(10 \mathrm{mmol} / \mathrm{l})$. Endotracheal aspirates were obtained each day, autolyzed and analyzed for pepsin by LC-MS/MS (LGC Ltd., London, UK). Non-nutritional calories from propofol were recorded.

Gastric emptying was assessed by the maximal concentration $\left(C_{\max }\right)$ of paracetamol $(1 \mathrm{~g})$ absorption at screening and day 4 [25]. Serum levels of GH, IGF-1, CRP, IL-6, IL-10 and electrocardiograms (ECGs) were obtained daily, and peak GH, IGF-1 and ulimorelin plasma concentrations were measured at the end of drug infusions.

Patients discontinued the study drug if they were discharged from the ICU, discontinued tube feedings, developed a severe or serious adverse event that was deemed related to the study drug, or treatment failure, defined as the need for another prokinetic medication, small bowel feedings or total parenteral nutrition. When the study drug or feeding protocol was terminated early, all safety and laboratory procedures were continued through study completion.

\section{Outcomes}

Efficacy end points The primary efficacy end point was the median daily average percentage of DPP received through enteral nutrition over the 5 days of treatment with the study drug. The secondary efficacy end point was the median daily average percentage of DCP. Other efficacy end points included feeding success, defined as receiving $80 \%$ of DPP; recurrence of intolerance $(\mathrm{GRV} \geq 500 \mathrm{ml})$; vomiting and regurgitation; gastric emptying; episodes of pepsin in tracheal aspirates; ventilatorfree days and 30-day mortality. Patients were assessed for pulmonary infection up to 3 days following the final dose of study drug, employing a previously described method [26].

Safety end points Safety end points included AEs, ECGs, laboratory data and 30-day mortality. Patients were followed for AEs from the signing of informed consent through 3 days following the final dose of study drug.

\section{Statistical methods}

Study population The primary analysis population was a modified intention-to-treat (mITT) population, defined as patients who were randomized and received at least one dose of study drug.

Continuous end points were analyzed by paired or unpaired $t$-test for Gaussian distributions and by the Wilcoxon signed rank or Mann-Whitney test for nonparametric distribution, with the Gaussian distribution of continuous variables assessed by the Shapiro-Wilk test. Categorical end points were analyzed by Fisher's exact test. Site effects were evaluated using a logistic mixed effect model with treatment group and site as fixed and random effects. Normal gastric emptying was defined as paracetamol $C_{\max } 8100 \mathrm{ng} / \mathrm{ml}$ [25]. Durations of ICU and hospital stays were analyzed according to the Kaplan-Meier method considering discharge of ICU or hospital as the event. Patients who died prior to discharge from the ICU or hospital were censored at the time of death. The log-rank test was used to compare the duration of ICU stay between treatment groups. Associations among elevated GRV, pepsin in tracheal aspirates and the incidence of pulmonary infection were evaluated by non-parametric regression using Spearman regression coefficients (rho). Analyses were performed with SAS 9.4, and $\alpha \leq 0.05$ (two-sided) was used for statistical significance.

Patients who discontinued tube feeding because of resumption of oral intake were assumed to have reached $100 \%$ of DPP on all days from the point that oral intake commenced. Conversely, patients who otherwise discontinued enteral feedings or died prior to day 5 were assumed to have received $0 \%$ of DPP on the days from 
Table 1 Study population: baseline demographics

\begin{tabular}{|c|c|c|c|}
\hline & Ulimorelin $(n=62)$ & Metoclopramide $(n=58)$ & Total $(n=120$ \\
\hline \multicolumn{4}{|l|}{ Demographics } \\
\hline Age, years, mean (SD) & $59.4(13.5)$ & $57.3(17.3)$ & $58.4(15.4)$ \\
\hline Female, $n(\%)$ & $15(24.2)$ & $18(31.0)$ & $33(27.5)$ \\
\hline Male, $n(\%)$ & $47(75.8)$ & $40(69.0)$ & $87(72.5)$ \\
\hline Dry body weight at ICU admission, kg, mean (SD) & $85.5(16.4)$ & $82.4(16.9)$ & $84.0(16.6)$ \\
\hline Body mass index (BMI), kg/m², mean (SD) & $28.8(5.7)$ & $27.5(4.9)$ & $28.2(5.4)$ \\
\hline Days in ICU before 1st dose study drug, median [Q1, Q3] & $4.6[3.0,6.9]$ & $5.5[3.5,7.7]$ & $4.9[3.3,7.6]$ \\
\hline \multicolumn{4}{|l|}{ Reasons for ICU admission } \\
\hline Medical, $n(\%)$ & $40(64.5)$ & $36(62.1)$ & $76(63.3)$ \\
\hline Respiratory & $20(32.3)$ & $15(25.9)$ & $35(29.2)$ \\
\hline Neurologic & $9(14.5)$ & $9(15.5)$ & $18(15.0)$ \\
\hline Trauma & $5(8.1)$ & $4(6.9)$ & $9(7.5)$ \\
\hline Vascular & $5(8.1)$ & $0(0.0)$ & $5(4.2)$ \\
\hline Sepsis & $1(1.6)$ & $4(6.9)$ & $5(4.2)$ \\
\hline Gastrointestinal & $0(0.0)$ & $1(1.7)$ & $1(0.8)$ \\
\hline Metabolic & $0(0.0)$ & $1(1.7)$ & $1(0.8)$ \\
\hline Other & $1(1.6)$ & $2(3.4)$ & $3(2.5)$ \\
\hline Surgical, $n(\%)$ & $22(35.4)$ & $22(37.9)$ & $44(36.7)$ \\
\hline Trauma & $6(9.7)$ & $9(15.5)$ & $15(12.5)$ \\
\hline Neurologic & $7(11.3)$ & $2(3.4)$ & $9(7.5)$ \\
\hline Gastrointestinal & $4(6.5)$ & $1(1.7)$ & $8(4.2)$ \\
\hline Respiratory & $1(1.6)$ & $4(6.9)$ & $5(4.2)$ \\
\hline Vascular & $1(1.6)$ & $2(3.4)$ & $3(2.5)$ \\
\hline Other & $3(6.4)$ & $4(6.8)$ & $7(5.8)$ \\
\hline \multicolumn{4}{|l|}{ Risk scores, mean (SD) } \\
\hline APACHE II & $22.8(9.6)$ & $20.7(7.3)$ & $21.8(8.6)$ \\
\hline SOFA & $8.8(3.9)$ & $8.3(4.1)$ & $8.6(4.0)$ \\
\hline NUTRIC score & $4.9(2.3)$ & $4.4(2.2)$ & $4.7(2.3)$ \\
\hline \multicolumn{4}{|l|}{ Concomitant medications, $n(\%)$} \\
\hline Vasopressors & $29(46.8)$ & $25(43.1)$ & $54(45.0)$ \\
\hline Opiates & $10(16.1)$ & $12(20.7)$ & $22(18.3)$ \\
\hline Sedatives & $14(22.5)$ & $18(31.0)$ & $32(26.7)$ \\
\hline Paralytic agents & $9(14.5)$ & $4(6.5)$ & $13(10.8)$ \\
\hline Propofol & $11(17.7)$ & $5(8.6)$ & $16(13.3)$ \\
\hline \multicolumn{4}{|l|}{ Nutritional targets, median [Q1, Q3] } \\
\hline Daily protein prescription, g/kg/day & $1.3[1.2,1.3]$ & $1.3[1.2,1.3]$ & $1.3[1.2,1.3]$ \\
\hline Daily caloric prescription, kcal/kg/day & $25.0[25.0,25.1]$ & $25.0[25.0,25.8]$ & $25.0[25.0,25.2]$ \\
\hline
\end{tabular}

SD, standard deviation; Q1, Q3, first and third quartiles

Differences between groups were not statistically significant (Wilcoxon signed rank test)

the point that enteral nutrition ceased. In situations where the primary or secondary end point was missing for reasons where imputation of $0 \%$ or $100 \%$ was not reasonable, multiple imputations were performed by a data review committee on blinded data using non-missing days to impute the missing days. Sensitivity analyses were performed by imputing the missing values following the distribution of the other arm and by excluding patients with missing data.
Sample size A total of 120 evaluable patients (60 in the ulimorelin arm and 60 in the metoclopramide arm) were estimated to provide $80 \%$ power and a two-sided $\alpha$ of 0.05 to demonstrate the superiority of ulimorelin versus metoclopramide with respect to the primary end point. This assumed a within-group standard deviation (SD) of $25 \%$, a $15 \%$ increase in DPP between the ulimorelin and metoclopramide treatment arms, and $15 \%$ of patients included in the mITT analysis despite receiving nil to 
minimal enteral feedings because of death, surgical procedures or disruptions unrelated to intolerance.

\section{Results}

\section{Patient demographics and disposition}

The CONSORT diagram is shown in Supplementary Fig. 2. Four hundred patients were screened, 122 randomized and 120 dosed. Baseline demographics were comparable between the two treatment groups (Table 1).

Of the patients, $74.2 \%$ completed 5 days of therapy or advanced to oral feedings; $25.8 \%$ terminated feedings before the completion of the 5-day treatment period. Most early terminations of treatment were for reasons unrelated to feeding; only $10.0 \%$ of patients terminated for treatment failure (Supplementary Table 1).

\section{Efficacy}

The primary end point, the daily average \%DPP received through enteral nutrition on efficacy phase days 1 through 5, was not different between groups. The median [Q1, Q3] \%DPPs achieved across the 5 days of treatment, days $1-5$, were $82.9 \%$ [38.4\%, 100.2\%] and $82.3 \%$ $[65.6 \%, 100.2 \%]$ for the ulimorelin and metoclopramide treatment groups, respectively $(p=0.49)$, with no differences on any of the individual 5 treatment days (Fig. 1). Median calories from propofol were $24 \mathrm{kcal} /$ day in both treatment groups, and only eight patients received protein supplements. The daily average percentage of DCP received through enteral nutrition co-varied exactly with the primary end point.

Of the ulimorelin and metoclopramide patients, 51.6\% and $55.2 \%$ achieved feeding success over the 5 days of treatment (Fig. 2a). Feeding success rates increased to $67.7 \%$ and $70.6 \%$ for ulimorelin and metoclopramide, respectively, when terminations for reasons unrelated to feeding were excluded. Although rates of feeding success improved with each study day, this was attributed, in part, to patient withdrawals.

Of the ulimorelin and metoclopramide patients, 50.0\% and $56.9 \%$ had one or more episodes of EFI recurrence during the trial, but rates declined progressively; by day 5 , only $13.2 \%$ and $17.4 \%$ of patients continued to have EFI episodes (Fig. 2b). Twenty-two percent and $17.2 \%$ experienced one or more episodes of regurgitation during the 5 days of feeding (Fig. 2c), but $<8.1 \%$ of patients experienced an episode on any single day; $33.9 \%$ and $31.0 \%$ of patients had a positive tracheal aspirate over the 5 days of treatment, but rates declined steadily over the treatment duration (Fig. 2d).

Of the ulimorelin-treated patients $81.3 \%$ and of metoclopramide-treated patients $83.3 \%$ had delayed GE by $C_{\max }$ at baseline; mean (SD) increases in $C_{\max }$ on day 4

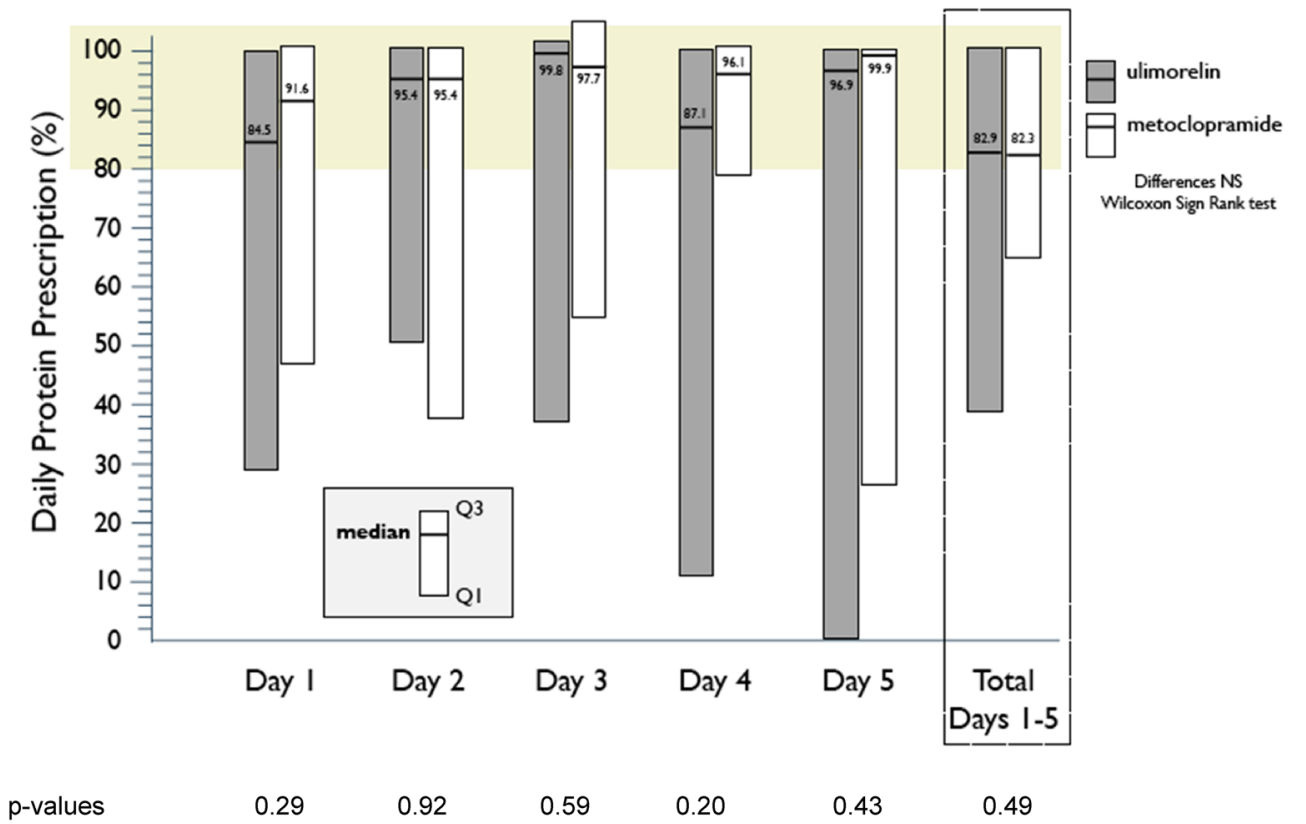

Fig. 1 Primary end point of the trial, the \% daily protein prescription achieved through enteral nutrition on days 1 through 5 and on individual study days. The results are expressed as median [1st quartile, 3rd quartile]. High median \%DPP rates are noted on each of the study days commencing with day 1 . Median percentages for days $1-5$ and the totals for the 5 days include all patients dosed (ulimorelin 62, metoclopramide 58), imputing values for patients with missing data, as discussed in "Methods." No significant differences were noted between treatment groups over the 5 days of study drug administration or any of the study days (Wilcoxon signed rank test). The shaded area represents $\geq 80 \%$ DPP achieved 
were 98.2\% (335.5) and 76.7\% (121.2) for ulimorelin vs. metoclopramide, respectively $(p=0.77)$. Target ulimorelin plasma concentrations were achieved in $98 \%$ of patients.

Ulimorelin and metoclopramide patients experienced similar ventilator-free days, ICU length of stay, hospital length of stay and incidences of ICU-acquired pneumonia (Supplementary Table 2). On linear regression, no associations were noted between the number of episodes of elevated GRV and the incidence of a positive tracheal aspirate for pepsin $\left(p=0.12, r^{2}=0.009\right)$. Likewise, no association was noted between the occurrence of an elevated GRV or positive tracheal aspirate for pepsin and the incidence of pulmonary infection (Table 2). Changes in GH, IGF-1 and inflammatory markers are shown in Supplementary Table 3.

\section{Safety}

The proportions of AEs and SAEs were similar between the two treatment groups. A greater proportion of ulimorelin-treated patients experienced an SAE or an adverse event leading to death, while a greater proportion of metoclopramide-treated patients experienced an $\mathrm{AE}$ leading to study drug discontinuation (Table 3). None of these differences were statistically significant.

The incidences of delirium, agitation and anxiety were similar between treatment groups. Mean glucose levels were significantly higher in ulimorelin vs. metoclopramide patients [mean (SD) 9.12 (1.82) vs. 8.31 (1.97) $\mathrm{mmol} / \mathrm{l}, p=0.009$ ]. Two patients in each of the treatment arms experienced AEs of QT interval prolongation. ECG parameters, including QTcF intervals, were similar between treatment groups: there were no significant differences in the incidences of ventricular tachycardia or ventricular fibrillation. Atrial fibrillation (AF) was

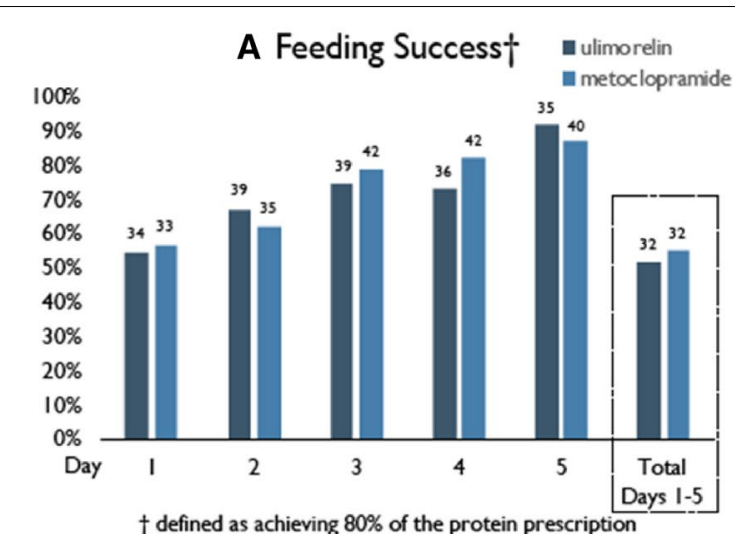

C Vomiting or Regurgitation

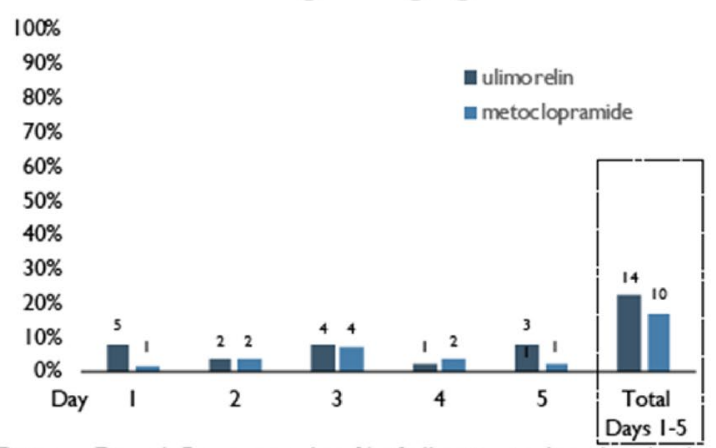

B EFI Recurrence (one or more episodes of GRV $\geq 500 \mathrm{~mL}) \dagger \dagger$

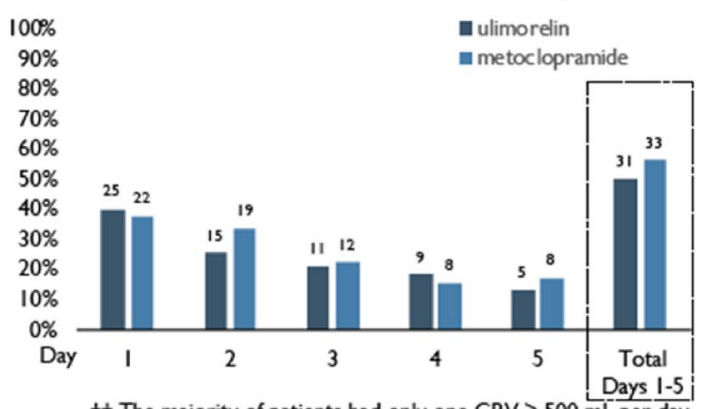

I† The majority of patients had only one GRV $\geq 500 \mathrm{~mL}$ per day

D Tracheal Aspirate Positive for Pepsin

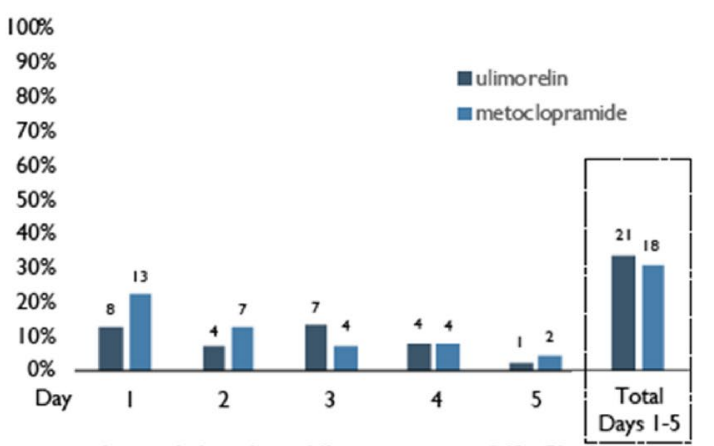

Data on Days I-5 expressed as \% of all patients dosed, individual days as \% of patients in the trial that day. All comparisons NS, Chi-Square test

Fig. 2 Rates of $\mathbf{a}$ feeding success, $\mathbf{b}$ episodes of recurrent EFI (GRV $\geq 500 \mathrm{ml}$ ), c vomiting or regurgitation and $\mathbf{d}$ a positive tracheal aspirate for pepsin on each of the study days, days 1-5, and over the 5 days of the study. Totals, days $1-5$, represent the percentages of patients who achieved feeding success over the 5 study days or the total numbers of patients who experienced one or more episodes of EFI recurrence, vomiting or regurgitation, or a positive tracheal aspirate for pepsin on any of the 5 study days, as the percentage of patients dosed. The proportions on individual days are expressed as the percentages of subjects remaining in the trial each day $[n=62,58,52,49$ and 38 (ulimorelin) and 58,56, 53, 51 and 46 (metoclopramide), days 1 through 5, respectively]. None of the differences between treatment groups were statistically significant (chi-squared test). While the daily proportions of patients with feeding success increased, in part because of the declining number of patients remaining in the trial, daily declines are evident in the percentages of patients who experienced EFI recurrence or a positive tracheal aspirate for pepsin 
Table 2 Associations among episodes of intolerance (GRV $\geq 500 \mathrm{ml}$ ), aspiration and pulmonary infection

\begin{tabular}{|c|c|c|c|c|c|c|c|}
\hline \multirow[t]{2}{*}{ Pulmonary infection } & \multicolumn{5}{|c|}{ Patients with GRV $\geq 500 \mathrm{ml}$, by number of episodes experienced } & \multirow[t]{2}{*}{$\rho$} & \multirow[t]{2}{*}{$p$ value } \\
\hline & $0(n=56)$ & $1(n=14)$ & $2(n=11)$ & $3(n=11)$ & $\geq 4(n=28)$ & & \\
\hline ICU-acquired pneumonia, $n$ (\%) & $10(17.9)$ & $4(28.6)$ & $2(18.2)$ & $1(9.1)$ & $7(25.0)$ & 0.05 & 0.48 \\
\hline $\begin{array}{l}\text { Lower respiratory tract infection } \\
\text { (excluding pneumonia), } n(\%)\end{array}$ & $11(19.6)$ & $4(28.6)$ & $3(27.3)$ & $1(9.1)$ & $9(32.1)$ & 0.08 & 0.28 \\
\hline \multicolumn{8}{|c|}{ (B) Relationship between positive tracheal aspirates for pepsin and pulmonary infection } \\
\hline \multirow[t]{2}{*}{ Pulmonary infection } & \multicolumn{5}{|c|}{$\begin{array}{l}\text { Patients with tracheal aspirates positive for pepsin, by number of positive aspi- } \\
\text { rates }\end{array}$} & \multirow[t]{2}{*}{$\rho$} & \multirow[t]{2}{*}{$p$ value } \\
\hline & $\begin{array}{l}0(n=75) \\
n(\%)\end{array}$ & $\begin{array}{l}1(n=20) \\
n(\%)\end{array}$ & $\begin{array}{l}2(n=10) \\
n(\%)\end{array}$ & & $e(n=9)$ & & \\
\hline ICU-acquired pneumonia & $19(25.3)$ & $2(10.0)$ & $1(10.0)$ & & & 0.17 & 0.067 \\
\hline $\begin{array}{l}\text { Lower respiratory tract infection } \\
\text { (excluding pneumonia) }\end{array}$ & $21(28.0)$ & $2(10.0)$ & $3(30.0)$ & & & 0.13 & 0.17 \\
\hline
\end{tabular}

$p$ value from the Spearman correlation coefficient

(A) Relationship between GRV elevation ( $\geq 500 \mathrm{ml}$ ) and the incidence of pulmonary infection, expressed as the number patients and the number of episodes of GRV elevation experienced by that patient over the 5-day treatment period post-randomization; (B) relationship between positive tracheal aspirates for pepsin and incidence of pulmonary infection, expressed as the number patients and number of aspirates positive for pepsin in that patient over the 5-day treatment period post-randomization. Definitions of ICU-acquired pneumonia and lower respiratory infection were per Heyland [33]. For these analyses, the two treatment groups were combined. Differences between patient groups were not statistically significant by chi-squared test

observed in higher incidence in metoclopramide (13.8\%) vs. ulimorelin $(1.6 \%)(p=0.014)$, resulting in discontinuation in one metoclopramide patient.

Thirty-day mortality was $30.6 \%$ in the ulimorelin group and $25.9 \%$ in the metoclopramide group $(p=0.69)$, with no differences in underlying causes of death.

\section{Discussion}

This was the largest prospective randomized clinical trial to date on the treatment of enteral feeding intolerance. No differences were noted in the primary end point of the trial, the percentage of the daily protein prescription (DPP) over 5 days of treatment. Although $>50 \%$ of patients experienced one or more recurrent EFI episode post initiation of treatment, the incidence of EFI declined with each study day, and the majority of patients achieved feeding success.

The primary efficacy end point was based on protein delivery because protein has been determined to one of the most important nutritional factors impacting ICU outcome $[27,28]$. The protein composition of the enteral formulas used in the study was maintained within a narrow range so that the primary end point would reflect the volume of formula delivered and gastric emptying.

The safety profiles of ulimorelin and metoclopramide were comparable. The incidences of delirium and agitation, which have been associated with metoclopramide administration, were no different between treatment groups. Unlike metoclopramide, ulimorelin has not been associated with these side effects and does not penetrate the CNS [21, 29]. Likewise, no differences in ECG intervals or ventricular arrhythmias were observed. Of interest, metoclopramide was associated with a significantly higher number of episodes of AF compared with ulimorelin, but this incidence (13.8\%) was comparable to its reported incidence in other ICU trials (10.5\%) [30]. Ghrelin agonists have been shown to enhance vagal tone [31], which could have suppressed AF events.

Metoclopramide is ordinarily administered as a slow 10 -ml syringe push over $2-3 \mathrm{~min}$ [22], but in the current study, metoclopramide was administered as a $50-\mathrm{ml}$ infusion over $30 \mathrm{~min}$. This modification was made to avoid the need for administrations of the two blinded study medications by syringe pushes and infusions. It has been suggested that the cardiotoxicity of metoclopramide results from inadvertently rapid injection [32], and it is possible that the cardiotoxicity of metoclopramide was minimized by slower infusion. The exclusion of patients with significant QT prolongation, instituted at the request of one of the regulatory agencies, may have also masked cardiotoxic drug effects.

Although this study did not demonstrate efficacy of either agent compared with placebo, the $\mathrm{GH}$, gastric emptying and blood glucose data suggested that ulimorelin had a relevant biologic effect. An unresolved question was whether the prokinetic effects of ulimorelin 
Table 3 Summary of adverse events (AEs)

\begin{tabular}{|c|c|c|c|}
\hline & $\begin{array}{l}\text { Ulimorelin }(n=62) \\
n(\%)\end{array}$ & $\begin{array}{l}\text { Metoclopramide }(n=58) \\
n(\%)\end{array}$ & $\begin{array}{l}\text { Total }(n=120) \\
n(\%)\end{array}$ \\
\hline AEs, total & $48(77.4)$ & $47(81.0)$ & $95(79.2)$ \\
\hline Severe AEs & $19(30.6)$ & $13(22.4)$ & $32(26.7)$ \\
\hline Serious adverse events (SAEs) & $3(4.8)$ & $3(5.2)$ & $6(5.0)$ \\
\hline AEs leading to study drug discontinuation ${ }^{a}$ & $3(4.8)$ & $6(10.3)$ & $9(7.5)$ \\
\hline Death due to an adverse event ${ }^{b}$ & $3(4.8)$ & $1(1.7)$ & $4(3.3)$ \\
\hline 30-day mortality & $19(30.6)$ & $15(25.9)$ & $34(28.3)$ \\
\hline \multicolumn{4}{|l|}{ AEs occurring in $\geq 5 \%$ of patients ${ }^{c}$} \\
\hline \multicolumn{4}{|l|}{ CNS } \\
\hline Agitation & $7(11.3)$ & $3(5.5)$ & $10(8.3)$ \\
\hline Anxiety & $1(1.6)$ & $3(5.2)$ & $4(3.3)$ \\
\hline Delirium & $9(14.5)$ & $6(10.3)$ & $15(12.5)$ \\
\hline \multicolumn{4}{|l|}{ Cardiovascular } \\
\hline Atrial fibrillation & $1(1.6)$ & $8(13.8)^{\dagger}$ & $9(7.5)$ \\
\hline Supraventricular tachycardia & $2(3.2)$ & $3(5.2)$ & $5(4.2)$ \\
\hline Hypertension & $3(4.8)$ & $4(6.9)$ & $7(5.8)$ \\
\hline QT interval prolongation ${ }^{d}$ & $2(3.2)$ & $2(3.4)$ & $4(3.3)$ \\
\hline Ventricular fibrillation ${ }^{\mathrm{d}}$ & $0(0.0)$ & $1(1.7)$ & $1(0.8)$ \\
\hline Ventricular tachycardia & $2(3.2)$ & $3(5.2)$ & $5(4.1)$ \\
\hline \multicolumn{4}{|l|}{ Respiratory } \\
\hline Pneumonia & $3(4.8)$ & $6(10.3)$ & $9(7.5)$ \\
\hline Prolonged mechanical ventilation & $6(9.7)$ & $7(12.1)$ & $13(10.8)$ \\
\hline \multicolumn{4}{|l|}{ Metabolic } \\
\hline Hyperglycemia & $8(12.9)$ & $8(13.8)$ & $16(13.8)$ \\
\hline Hypophosphatemia & $4(6.5)$ & $1(1.7)$ & $5(4.3)$ \\
\hline \multicolumn{4}{|l|}{ Other } \\
\hline Acute kidney injury & $7(11.3)$ & $3(5.2)$ & $10(8.3)$ \\
\hline Anemia & $6(9.7)$ & $5(8.6)$ & $11(9.2)$ \\
\hline Constipation & $2(3.2)$ & $0(6.9)$ & $2(1.7)$ \\
\hline Edema & $5(8.1)$ & $5(8.6)$ & $10(8.3)$ \\
\hline Elevated AST & $1(1.6)$ & $3(5.2)$ & $4(3.3)$ \\
\hline Fever & $4(6.5)$ & $3(5.2)$ & $7(5.8)$ \\
\hline
\end{tabular}

AST, aspartate amino transferase

${ }^{+} p=0.014$; other differences were not statistically significant (chi-squared test)

${ }^{a}$ AEs leading to study drug discontinuation: ulimorelin: failed stem cell bone marrow transplant, increased intracranial pressure and delirium; metoclopramide: diarrhea, paracetamol overdose, QT interval prolongation, delirium, atrial fibrillation and gastrointestinal bleeding

${ }^{b}$ AEs leading to death, including the 5-day period of study drug treatment and the 3-day period following the final dose of study drug: ulimorelin; failed stem cell transplantation, progressive pulmonary disease and increased intracranial pressure; metoclopramide: progressive pulmonary disease

${ }^{c}$ AEs occurring in $\geq 5 \%$ of patients in either treatment arm; ${ }^{d}$ incidences of QT prolongation and ventricular fibrillation are shown although they did not reach this reporting threshold

and metoclopramide were meaningful or whether EFI was merely a self-limited condition, as suggested by the declining rates of EFI recurrence over the 5 days of the study. Nguyen compared metoclopramide with erythromycin over 7 days of treatment using a Kaplan-Meier survival analysis of patients not experiencing another episode intolerance [11]. The GRV used to define EFI in this trial was $250 \mathrm{ml}$, and patients were censored after the first episode of EFI recurrence. Only $16 \%$ of metoclopramide and $31 \%$ of erythromycin patients met feeding goals through day 7 . However, the current trial demonstrates that high success rates can be achieved when a GRV of $500 \mathrm{ml}$ is employed and patients continue to be fed after EFI recurs. While a GRV of $250 \mathrm{ml}$ has been associated with delayed GE, it has not been shown to have clinical relevance [33]. 
In the current trial, feeding success rates were high, and the rates of vomiting or regurgitation, aspiration and pulmonary infection were low compared with other ICU studies [34, 35]. Furthermore, no association could be shown among the incidences of GRV elevation, aspiration and pulmonary infection. These findings suggest that a definition of EFI more stringent than a single episode of $500 \mathrm{ml}$ might be needed in clinical practice. These findings also suggest that volume-based feeding could be safe in EFI when a prokinetic agent is employed. This conclusion should be confirmed in other studies, and no extrapolations should be made to other causes of intolerance, such as paralytic ileus, bowel distension, Ogilvie syndrome, bowel ischemia or severe diarrhea.

The strengths of this study were that treatments were blinded and randomized, a standard feeding protocol was used with the standard for formula composition, and a standard definition of EFI $(500 \mathrm{ml})$ was employed that conformed to recent guidelines. Patients were also followed for 5 days irrespective of whether EFI was again encountered, a procedure that showed that patients can be fed to goal despite EFI recurrence. The weakness of the study was that it was comparator, not placebo, controlled, a design implemented when it was determined that investigators would not enroll patients into a placebo-controlled study and/or that ethics committees would not approve one.

\section{Conclusion}

In this randomized controlled trial of critically ill patients with EFI, we were unable to observe differences between ulimorelin and metoclopramide in the median percentages of target nutrition achieved or the proportions of patients with feeding success, and the safety profiles of ulimorelin and metoclopramide were generally comparable, with low rates of vomiting, regurgitation and aspiration.

\section{Electronic supplementary materia}

The online version of this article (https://doi.org/10.1007/s00134-019-05593-2) contains supplementary material, which is available to authorized users.

\begin{abstract}
Author details
${ }^{1}$ Queen's University, Kingston, ON, Canada. ${ }^{2}$ Gelderse Vallei Hospital, Ede, The Netherlands. ${ }^{3}$ Hospital Universitario Doce de Octubre, Madrid, Spain. ${ }^{4}$ Ohio State University, Columbus, OH, USA. ${ }^{5}$ Medisch Spectrum Twente, Enschede, The Netherlands. ${ }^{6}$ Canisius-Wilhelmina Ziekenhuis, Nijmegen, The Netherlands. ${ }^{7}$ Hospital Universitari Germans Trias i Pujol, Badalona, Spain. ${ }^{8}$ Eastern Idaho Regional Medical Center, Idaho Falls, ID, USA. ${ }^{9}$ University of Toronto, Toronto, Canada. ${ }^{10}$ Pivotal SL, Madrid, Spain. ${ }^{11}$ Lyric Pharmaceuticals, San Francisco, CA, USA. ${ }^{12}$ Georgetown University School of Medicine, Washington, DC, USA.
\end{abstract}

\section{Acknowledgements}

This study was funded by Lyric Pharmaceuticals, South San Francisco, CA, USA. The authors wish to thank the following investigators who dedicated their time and effort to the PROMOTE trial: Lead Study Investigator: Daren K
Heyland, Queens University, Kingston, ON, Canada. USA: David Evans, Wexner Medical Center, The Ohio State University, Columbus, $\mathrm{OH}$ (Lead Investigator, US); Sarah Jolley, Louisiana State University Health Science Center-New Orleans, New Orleans, LA; Ronald Raines, Rockies Regional Medical Center, Colorado Springs, CO; Kenneth Krell, Eastern Idaho Regional Medical Center, Idaho Falls, ID. Spain: Teodoro Grau-Carmona, Hospital Universitario Doce de Octubre, Madrid (Lead Investigator); Lluis Serviá-Goixart, Hospital Arnau de Vilanova, Lleida; Sonia Perez-Quesada, Hospital General de Alicante, Alicante; Jose Ignacio Herrero-Meseguer, Hospital Universitario de Bellvitge, BarceIona; Enrique Calvo-Herranz, Hospital Universitario de Getafe, Getafe; Carol Lorencio, Hospital Universitario Josep Trueta, Girona; Amparo Peredes, Hospital Qurónsalud Sur, Alcorcón; Juan Carlos Yébenes-Reyes, Hospital de Mataró, Mataró; Miguel Angel Garcia-Martinez, Hospital de Torrevieja, Torrevieja; Manuel Cervera, Hospital Dr. Peset, Valencia; Maria Luisa Bordejé, Hospital Universitari Germans Trias i Pujol, Badalona; Juan Franscisco Fernadez-Ortega, Hospital Universitario Carlos Haya, Malaga; Inmaculada Fernández-González, Hospital Quiron San Camilo, Madrid. The Netherlands: Arthur van Zanten (Lead Investigator), Gelderse Vallei Hospital, Ede; Albertus Beishuizen, Medisch Spectrum Twente, Enschede; Jeroen Schouten, Canisius Wilhelmina Ziekenhuis, Nijmegen; Oscar Hoiting, Canisius Wilhelmina Ziekenhuis, Nijmegen. Canada: Tom Stelfox, University of Alberta, Calgary; Juan Posadas, University of Alberta, Calgary.

\section{Compliance with ethical standards}

\section{Conflicts of interest}

Dr. Heyland served as a consultant to Lyric Pharmaceuticals in the design and execution of this trial. Dr. James, Dr. Harris and Mr. Brown were employees of Lyric Pharmaceuticals. Dr. Gonzalez and Mr. Perez were employees of Pivotal $\mathrm{SL}$, the clinical research organization that conducted the trial on behalf of Lyric.

\section{Ethical approval}

The Institutional Review Boards (IRBs)/Independent Ethics Committees (ECs) approved the study protocol at all participating sites.

\section{Access to the full trial protocol and data}

The full trial protocol and trial data supporting this publication can be obtained by contacting the corresponding author.

\section{Publisher's Note}

Springer Nature remains neutral with regard to jurisdictional claims in published maps and institutional affiliations.

Received: 12 December 2018 Accepted: 4 March 2019

\section{References}

1. Gungabissoon U, Hacquoil K, Bains C, Irizarry M, Dukes G et al (2014) Prevalence, risk factors, clinical consequences, and treatment of enteral feed intolerance during critical illness. JPEN 39:441-448

2. Reintam Blaser A, Starkopf J, Kirismägi Ü, Deane AM (2014) Definition, prevalence, and outcome of feeding intolerance in intensive care: a systematic review and meta-analysis. Acta Anaesthesiol Scand 58:914-922

3. Chapman MJ, Besanko LK, Burgstad CM, Fraser RJ, Bellon M et al (2011) Gastric emptying of a liquid nutrient meal in the critically ill: relationship between scintigraphic and carbon breath test measurement. Gut 60:1336-1343

4. Elke G, Feibinger TW, Heyland DK (2015) Gastric residual volume in critically ill patients: a dead marker or still alive? Nutr Clin Pract 30:59-71

5. McClave SA, Taylor BE, Martindale RG, Warren MM, Johnson DR et al (2016) Guidelines for the provision and assessment of nutrition support therapy in the adult critically ill patient: Society of Critical Care Medicine (SCCM) and Society for Parenteral and Enteral Nutrition (ASPEN). JPEN 40:159-211 
6. Reintam Blaser A, Startkopf J, Alhazzani W, Berger MM, Casaer MP et al (2017) Early enteral nutrition in critically ill patients: ESICM clinical practice guidelines. Intensive Care Med 43:380-398

7. Singer P, Blaser AR, Berger MM, Alhazzani W, Calder PC, Casaer MP, Hiesmayr M, Mayer K, Montejo JC, Pichard C, Preiser JC, van Zanten ARH, Oczkowski S, Szczeklik W, Bischoff SC (2019) ESPEN guideline on clinical nutrition in the intensive care unit. Clin Nutr 38:48-79. https://doi. org/10.1016/j.clnu.2018.08.037

8. Ukleja A (2010) Altered Gl motility in critically ill patients: current understanding of pathophysiology, clinical impact, and diagnostic approach. Nutr Clin Pract 25:16-25

9. Heyland DK, Dhaliwal R, Drover JW, Gramlich L, Dodek P (2003) Canadian clinical practice guidelines for nutrition support in mechanically ventilated, critically ill adult patients. JPEN 27:355-373

10. European Medicines Agency (2013) European Medicines Agency recommends changes to the use of metoclopramide, 26 July 2013 EMA/44303/2013

11. Nguyen NQ, Chapman NJ, Fraser RJ, Bryant LK, Holloway RH (2007) Erythromycin is more effective than metoclopramide in the treatment of feeding intolerance in critical illness. Crit Care Med 35:483-489

12. Dass NB, Munonyara M, Bassil AK, Hervieu GJ, Osbourne S et al (2003) Growth hormone secretagogue receptors in rat and human gastrointestinal tract and the effects of ghrelin. Neuroscience 120:443-453

13. Camilleri M, Papathanasopolous A, Odunsi S (2009) Actions and therapeutic pathways of ghrelin for gastrointestinal disorders. Nat Rev Gastroenterol Hepatol 6:342-352

14. Nass R, Gaylinn BD, Thorner MO (2011) The tole of ghrelin in GH secretion and GH disorders. Mol Cell Endocrinol 340:10-14

15. Nagaya N, Itoh T, Murakami S, Oya H, Uematsu M et al (2005) Treatment of cachexia with ghrelin in patients with COPD. Chest 126:1187-1193

16. Temel JS, Abernethy AP, Currow DC, Friend J, Duus EM et al (2016) Anamorelin in patients with non-small-cell lung cancer and cachexia (ROMANA 1 and ROMANA 2): results from two randomized, double-blind, phase 3 trials. Lancet 17:519-531

17. Jacob A, Wu R, Zhou M, Coppa GF, Wang P (2010) Mechanism of the inhibitory effect of ghrelin in sepsis. Hepat Med Evid Res 2:33-38

18. Deane A, Chapman MJ, Fraser RJL, Horowitz M (2010) Bench-to-bedside review: the gut as an endocrine organ in the critically ill. Crit Care 14:228-237

19. Venkova K, Fraser G, Greenwood-van Hoveyda HR, Meervald B (2007) Prokinetic effects of a new ghrelin receptor agonist TZP-101 in a rat model of post-operative ileus. Dig Dis Sci 52:2241-2248

20. Ejskaer N, Dimcevski G, Wo J, Helstrom PM, Gormsen LC et al (2010) Safety and efficacy of ghrelin agonist TZP-101 in relieving symptoms in patients with diabetic gastroparesis: a randomized, placebo-controlled study. Neurogastroenterol Motil 22:1069-1078

21. Shaw M, Pediconi C, McVey D, Mondou E, Quinn J et al (2013) Safety and efficacy of ulimorelin administered postoperatively to accelerate recovery of gastrointestinal motility following partial bowel resection: results of two randomized, placebo-controlled phase 3 trials. Dis Col Rectum 56:888-897

22. Global RxPh. Metoclopramide. http://www.globalrph.com/renal/metoc lopramide/. Accessed 6 Dec 2018

23. Peterson CM, Thomas DM, Blackburn GL, Heymsfield SB (2016) Universal equation for estimating ideal body weight and body weight at any BMM. Am J Clin Nutr 103:1197-1203

24. Heyland DK, Cahill NE, Dhaliwal R, Wang M, Day AG et al (2010) Enhanced protein-energy provision via the enteral route in critically ill patients: a single center feasibility trial of the PEP uP protocol. Crit Care 14:R78

25. James J, Doll W, Harris S (2018) Method to assess gastric emptying in the fed state in enterally tube fed patients: comparison of the paracetamol absorption test to scintigraphy. Crit Care 22(Suppl 1):135

26. Heyland DK, Cook D, Dodek P, Muscedere J, Day A (2006) A randomized trial of diagnostic techniques for ventilator-associated pneumonia. N Engl J Med 355:2619-2630

27. Heyland DK (2015) Should we PERMIT systemic underfeeding in all intensive care unit patients? Integrating the results of the PERMIT study in our clinical practice guidelines. JPEN 40:156-168

28. Nicolo M, Heyland DK, Chittams J, Sammarco T, Compher C (2016) Clinica outcomes related to protein delivery in a critically ill population: a multicenter, multinational observation study. JPEN 40:45-51

29. Pusovit RV, Callaghan B, Kosari S, Rivera LR, Thomas H et al (2014) The mechanism of enhanced defecation caused by the ghrelin receptor agonist, ulimorelin. Neurogastroenterol Motil 26:264-271

30. Kanji S, Williamson DR, Mohammadzadeh Yaghchi B, Albert M, Mclntyre $L$ (2012) Epidemiology and management of atrial fibrillation in medical and noncardiac surgical adult intensive care unit patients. J Crit Care 27:326-332

31. Avau B, Carbone F, Tack J, DePoortere I (2013) Ghrelin signaling in the gut, its properties, and therapeutic potential. Neurogastroenterol Motil 25:720-732

32. Rumore MM (2012) Cardiovascular adverse effects of metoclopramide: review of literature. IJCRI 3:1-10

33. Montejo JC, Miñambres E, Bordejé L, Mesejo A, Acosta J et al (2010) Gastric residual volume during enteral nutrition in ICU patients: the REGANE study. Intensive Care Med 36:1386-1393

34. Reigner J, Mercier E, Le Gouge A, Boulain T, Desachy A et al (2013) Effect of not monitoring residual gastric volume on risk of ventilator-associated pneumonia in adults receiving mechanical ventilation and early enteral feeding: a randomized controlled trial. JAMA 209:249-256

35. Reigner J, Boisramé-Helms J, Brisard L, Lascarrou J-B, Ait Hassan A et al (2018) Enteral versus parenteral early nutrition in ventilated adults with shock: a randomized, controlled, multicenter, open-label, parallel-group study (NUTRIREA-2). Lancet 391:133-143 